Proceedings of the Online Conference "Applications of Physics in Mechanical and Material Engineering"

\title{
Investigation into Effect of Cooling Rate on Magnetic Properties of Alloys that Are Based on FeCoB Matrix
}

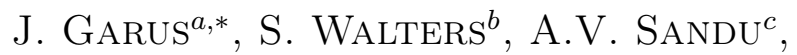 \\ M.M.A.B. ABDUllaH ${ }^{d}$, F.F. ZainaL ${ }^{d}$, \\ M.F. OMAR ${ }^{d}$, A. SEIFODdini ${ }^{e}$ AND P. MOUSAVI ${ }^{e}$ \\ ${ }^{a}$ Częstochowa University of Technology, al. Armii Krajowej 19, 42-200 Częstochowa, Poland \\ ${ }^{b}$ Advanced Engineering Centre, University of Brighton, BN2 4GJ, Brighton, United Kingdom \\ ${ }^{c}$ Gheorghe Asachi Technical University of Iasi, \\ Faculty of Materials Science and Engineering, Iasi, Romania \\ ${ }^{d}$ Centre of Excellence Geopolymer and Green Technology (CEGeoGTech), \\ Universiti Malaysia Perlis (UniMAP), 01000Kangar, Perlis, Malaysia \\ ${ }^{e}$ Department of Mining and Metallurgical Engineering, Yazd University, 89195-741, Yazd, Iran \\ Doi: $10.12693 /$ APhysPolA.139.544 \\ *e-mail: justyna.garus@pcz.pl
}

\begin{abstract}
The paper presents the results of tests carried out on samples of FeCoB-based alloys. The samples were produced by a technique involving the injection of each liquid alloy into a copper water-cooled mould. The investigated materials are characterised by much better properties than their crystalline counterparts with the same chemical composition. It has been shown that the cooling rate has a significant impact on the magnetic properties of the produced alloy. Alteration of the production parameters of $\mathrm{FeCoB}$ alloys has a decisive influence on the resulting properties of these alloys. The research has revealed evidence that changes in the structural characteristics are related directly to changes in the magnetic properties.
\end{abstract}

topics: magnetic properties, amorphous materials, coercive field, saturation magnetisation

\section{Introduction}

Development of physics, chemistry, metallurgy and materials engineering is conducive to obtaining new materials. Their production method may determine their values [1-3]. Further stages of the refinement of their properties are different treatment methods, e.g., annealing, heating, interference with a current pulse or a laser beam of different power [4-8]. In the 1990s, a new group of amorphous materials called bulk amorphous alloys was born [9-11]. Interestingly, these materials differed from their predecessors (classic amorphous materials in the form of ribbons $[12,13]$ ) only in their thickness. Later studies have shown that the thickness has great importance in the case of properties [14]. In order to produce bulk amorphous alloys, three criteria developed by A. Inoue and colleagues from the Tochoku University in Japan should be used [15]. It was assumed that the alloy should consist of more than three components whose atomic radii (at least the main components) will differ by more than $12 \%$ and the alloying components will have a negative heat of

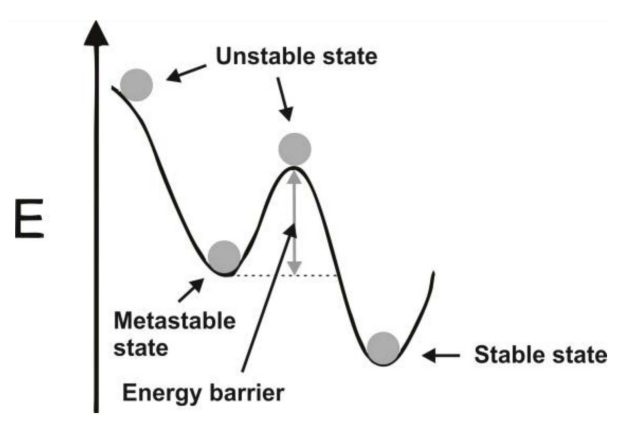

Fig. 1. Diagram showing the change in Gibbs free energy [16].

mixing. All these criteria are limiting the migration of atoms in the volume of the solidifying alloy, which - in turn - inhibits the formation of energetically privileged systems. An amorphous state is a thermodynamically unstable state, and adding energy to it ultimately leads to the formation of a periodic crystal lattice. Energy change diagram of the system (see Fig. 1) describes well Gibbs free energies [16]. 
A special group of bulk amorphous materials are ferromagnetic alloys showing soft magnetic properties [17]. This group includes mainly FeCoB-based alloys, which are widely studied in many scientific and industrial centers [17-24]. High hopes are placed in these materials in terms of reducing losses due to magnetization and operation of transformers at high frequencies. The commonly used FeSi transformer steels are produced in multiple stages, which ultimately translates into the cost of their production and environmental protection. Therefore, it is important to conduct constant research on modern, rapidly-cooled materials with an amorphous or nanocrystalline structure. The commonly used nanocrystallization methods rely on heating or annealing of an amorphous material, which is very sensitive to temperature and process time. A structure change can also be obtained as a result of the production process itself, which significantly shortens the preparation time of nanocrystalline materials and is considered as an economic factor.

This paper presents test results for rapidly-cooled $\mathrm{Fe}_{65} \mathrm{Nb}_{5} \mathrm{Y}_{7} \mathrm{Hf}_{3} \mathrm{~B}_{20}$ alloy produced at different cooling rates.

\section{Materials and methods}

Test samples were obtained from components of purity: $\mathrm{Fe}$ - 99.98; Co - 99.99; Y - 99.98; Hf - 99.98; B - 99.98. Alloy components were weighed out to four decimal places. In the first step, crystalline ingots were produced. The weighted material was placed in a cavity on a water-cooled copper plate. It was subsequently smelted in a vacuum furnace using plasma arc. Mixing of the alloy components consisted of several times turning the combined components and their re-melting. Always before melting, high vacuum was obtained inside the working chamber and flushed with an inert gas (Ar). At the final stage, an Ar vacuum of 0.7 bar was obtained. In order to purge the atmosphere of the remaining impurities, pure titanium was pre-melted to act as the absorbent remaining in the oxygen chamber.

Ingots prepared according to the above procedure were cleaned of oxides and impurities, first mechanically and then using an ultrasonic cleaner. Dividing the ingots into smaller batch portions was performed using a hydraulic press. The pieces of the ingot were used to make a rapidly-cooled sample by the injection method where liquid alloy was forced into a copper water cooled mold. The piece of the ingot was placed in a $12 \mathrm{~mm}$ diameter quartz tube with an opening against the $1.5 \mathrm{~mm}$ diameter mold. Using the eddy currents, the ingot was melted and the molten alloy was forced into the copper mold by passing argon through a tube. Samples were produced under the same conditions as for the ingot. The produced samples had the shape of plates with $0.5 \mathrm{~mm}$ thickness and area of $100 \mathrm{~mm}^{2}$.

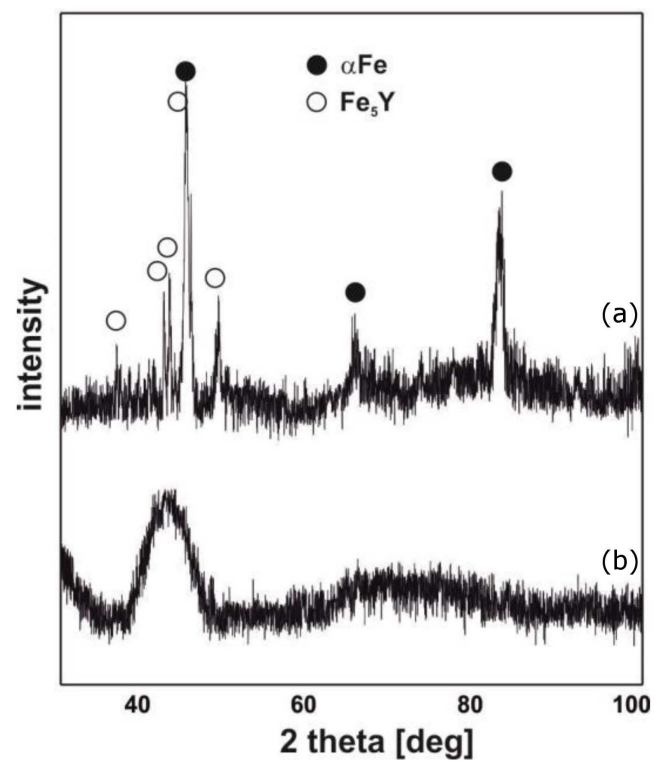

Fig. 2. X-ray diffraction patterns for the alloy samples: (a) crystal ingot, (b) rapidly-cooled sample.

Samples prepared in this way were tested for structure with the use of X-rays. For this purpose, an X-ray diffractometer by BRUKER model ADVANCE 8 was used. Measurements were made in the range of $30-100^{\circ}$ of $2 \theta$ angle, with the measuring step of $0.02^{\circ}$ and exposure time of $7 \mathrm{~s}$ per step. Measurements were made for low energy crushed samples in agate mortar within toluene. Performing the measurements for crushed samples makes it possible to obtain information from the entire volume. Measurements of magnetic properties were made with the use of a LAKESHORE 7307 VSM, operating in the range of magnetic field strength up to $2 \mathrm{~T}$. Both the structure and magnetic properties measurements were performed at room temperature.

\section{Results}

Figure 2 shows the X-ray diffraction images for the tested samples. The obtained diffraction patterns for the sample from the ingot and after the rapidly-cooling process differ significantly. The first diffractogram (see Fig. 2a) shows clear peaks originating from the crystalline phases present in the sample volume. In the case of the second diffractogram (Fig. 2b), only a broad, blurred halo typical for amorphous materials is visible. The solidification process on the copper plate does not ensure a sufficiently high cooling rate, which causes the migration of atoms and merging them into systems with lower energy. Lowering systems energy leads to the formation of crystal clusters within which nuclei of crystallization initially form, and then crystal grains and their propagation. Finally, the entire sample becomes crystalline and the grain growth stops due to reaching a thermodynamically stable state. 


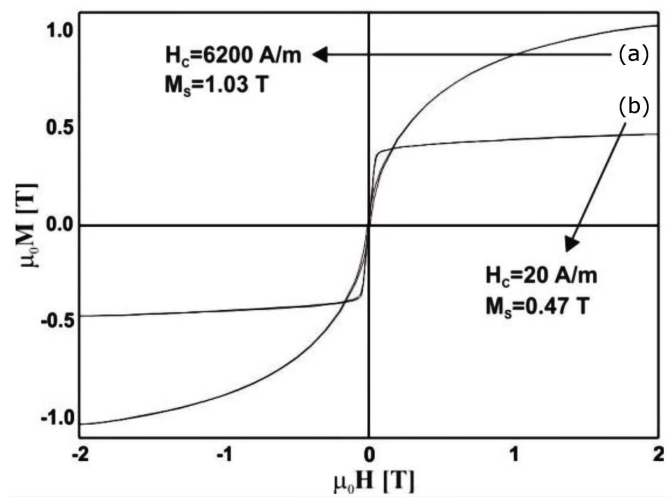

Fig. 3. Static magnetic hysteresis loops for the alloys: (a) cooling on a copper plate, (b) rapidlycooling.

Figure 3 shows the static magnetic hysteresis loops measured for the tested alloy. Static magnetic hysteresis loops for the tested alloy samples are similar. It is clearly visible that in both cases the tested material is a ferromagnetic material with soft magnetic properties. The change in the value of magnetization saturation and coercive field is the result of a different material structure, which has a direct impact on the magnetic structure. Magnetic interactions are the result of interactions between pairs of magnetic atoms. Determining the stiffness parameter $D_{\text {spf }}$ of the spin wave, one can indirectly infer the strength of the magnetic interactions. Parameter $D_{\mathrm{spf}}$ is related with other parameters by relation

$$
b=3.54 \mu_{0}\left(\frac{g \mu_{\mathrm{B}}}{4 \pi D_{\mathrm{spf}}}\right)^{3 / 2} k_{\mathrm{B}} T .
$$

Here, $b$ is the slope of the linear fit corresponding to the thermally-induced suppression of spin-waves by a magnetic field of high intensity, $\mu_{0}$ is the magnetic permeability of a vacuum, $k_{\mathrm{B}}$ - Boltzmann's constant, $\mu_{\mathrm{B}}$ - the Bohr magneton, $g$ - the gyromagnetic factor, and $T$ - the temperature.

The crystalline alloy is characterized by a saturation magnetization value of $1.03 \mathrm{~T}$, a coercive field of $6200 \mathrm{~A} / \mathrm{m}$ and a parameter value $D_{\text {spf }}=11.3 \mathrm{meV} \mathrm{nm}^{2}$. The alloy with the same chemical composition produced by injection casting is characterized by completely different properties. Namely, a much lower value of the coercive field $\left(H_{C}=20 \mathrm{~A} / \mathrm{m}\right)$ and saturation magnetization $\left(M_{S}=0.47 \mathrm{~T}\right)$ and a much higher value of parameter $D_{\text {spf }}=34.3 \mathrm{meV} \mathrm{nm}^{2}$.

\section{Conclusions}

The process of producing rapidly-cooled materials determines the evaluation of the structure and has a direct impact on ferromagnetic alloys properties. The appearance of a well-developed crystal structure without directional texturing significantly deteriorates the soft magnetic properties of this type of alloys.

\section{References}

[1] K. Błoch, M. Nabiałek, Acta Phys. Pol. A 127, 413 (2015).

[2] M.E. Mchenry, M.A. Willard, D.E. Laughlin, Prog. Mater. Sci. 44, 291 (1999).

[3] P. Rezaei-Shahreza, A. Seifoddini, S. Hasani, J. Non-Cryst. Solids 471, 286 (2017).

[4] P. Vizureanu, M. Nabiałek, A.V. Sandu, B. Jeż, Materials 13, 835 (2020).

[5] J. Gondro, J. Świerczek, J. Olszewski, J. Zbroszczyk, K. Sobczyk, W. Ciurzyńska, J. Rzącki, M. Nabiałek, J. Magn. Magn. Mater. 324, 1360 (2012).

[6] T. Alam, T. Borkar, S.S. Joshi, S. Katakam, X. Chenc, N.B. Dahotre, R.V. Ramanujan, R. Banerjee, J. NonCryst. Solids 428, 75 (2015).

[7] L.Y, Guo, S.N. Geng, J. Pang, Y.H. Hu, S. Lan, C.M. Wang, W.M. Wang, Mater. Des. 160, 538 (2018).

[8] P. Rezaei-Shahreza, A. Seifoddini, S. Hasani, J. Alloys Compd. 738, 197 (2018).

[9] J. Olszewski, J. Zbroszczyk, K. Sobczyk, W. Ciurzyńska, P. Brągiel, M. Nabiałek, J. Świerczek, M. Hasiak, A. Łukiewska, Acta Phys. Pol. A 114, 1659 (2008).

[10] A. Inoue, T. Zhang, T. Masumoto, Mater. Trans. JIM 31, 177 (1990).

[11] A. Inoue, A. Kato, T. Zhang, S.G. Kim, T. Masumoto, Mater. Trans. JIM 2, 609 (1991).

[12] P. Pietrusiewicz, K. Błoch, M. Nabiałek, S. Walters, Acta Phys. Pol. A 127, 397 (2015).

[13] A. Wang, C. Zhao, H. Men, A. He, C. Chang, X. Wang, R. Li, J. Alloys Compd. 630, 209 (2015).

[14] M. Nabiałek, S. Garus, Acta Phys. Pol. A 130, 1010 (2016).

[15] A. Takeuchi, A. Inoue, Mater. Trans. 46, 2817 (2005).

[16] V. Pop, in: Ecole Franco-Romanie: Magnétisme des SystéMesnanoscopiques es Structures Hybrides, Brasow (Romania), 2003.

[17] J. Gondro, K. Błoch, M. Nabiałek, S. Garus, Mater. Tehn. 50, 559 (2016).

[18] B. Jeż, Rev. de Chim. 68, 1903 (2017).

[19] P. Jia, E. Wang, K. Han, Materials 9, 899 (2016).

[20] K. Sarlar, I. Kucuk, J. Magn. Magn. Mater. 374, 607 (2015). 
[21] K. Jeż, B. Jeż, P. Pietrusiewicz, Rev. de Chim. 70, 3158 (2019).

[22] P. Vizureanu, Metal. Int. 14, 5 (2009).

[23] M. Nabiałek, B. Jeż, K. Błoch, J. Gondro, K. Jeż, A.V. Sandu, P. Pietrusiewicz, J. Alloys Compd. 820, 153420 (2020).

[24] P. Pietrusiewicz, M. Nabiałek, B. Jeż, Rev. de Chim. 69, 2097 (2018). 